\title{
ABOUT THE ANALYTICAL CALCULUS OF DENTAL BRIDGE WITH DISTAL EXTENSION AND SINGLE POLE TOOTH ASSIMILATED AS A BEAM BY TRANSFER-MATRIX METHOD (TMM)
}

\author{
Mihai Tripa ${ }^{1}$, Dorina Sorcoi ${ }^{2}$, Crenguta Florescu ${ }^{2}$, Adriana Sorcoi ${ }^{3}$, Mihaela Suciu ${ }^{2}$ \\ ${ }^{1}$ Department of Design \& Robotics, Technical University of Cluj-Napoca, Mihai.TRIPA@ muri.utcluj.ro,Romania \\ ${ }^{2}$ Department of Mechanical Engineering, Technical University of Cluj-Napoca, dorina_sorcoi@yahoo.com, \\ crenguta_florescu@yahoo.com, Mihaela.SUCIU@ rezi.utcluj.ro, Romania
}

${ }^{3}$ Department of Science and Material Engineering, Technical University of Cluj-Napoca, Adriana.Sorcoi@stm.utcluj.ro, Romania

Received: 24 December 2020; Accepted: 29 December 2020; Published: 31 December 2020

Abstract: This work presents a different, but an original approach for orthodontic problems about dental bridge studies. Assimilation of dental bridge with a beam is very important for practical applications in bio-engineering problems, in occurrence, in orthodontic fields. Beams studies and calculus are very interesting and easy with Transfer-Matrix Method (TMM). In this article, we study a dental bridge with distal extension and with a single pole, as a beam. A distal extension is an extension of posterior part of mouth, in contrast to a medial extension consisting in an extension to anterior part of oral cavity. In the first part, we present a study of beam with Dirac's and Heaviside's functions and operators. In second part, we present the TMM approach, which involves to consider the left end as a free end. The right end is pole and is embedded. We obtain a matrix relation, in which state vector of some face, is expressed function of state vector for the first face (origin face, or left face, meaning - the free end). Now, we can put the conditions at limit and on the end support, in two vectors at ends of beam. After, a linear equations system is solved. TMM algorithm can be very easy programmed and we can obtain all components of all state vectors: stresses and strains. In future research we hope to present experimental validation too.

Keywords- Ayurveda; Traditional Chinese Medicine; modern medicine; health care.

\section{INTRODUCTION}

Dental bridge assimilated with a beam is an approach very important for practical applications in bio-engineering problems, in occurrence, in orthodontic fields. Classical beam studies and calculus are presented in [6]. Study about another medicine domain, in orthopedics, is presented in [1]. [2] gives the importance for the health field of dental bridges in England and Wales. Bending fracture for dental bridges, with simulation analysis, test and experiments are shown in [3] and [4]. In [7] are presented studies about design of dental bridges. [8] gives a similarity between dental implant and buckling straight bar on elastic environment studied by TMM. Effects of small-grit grinding and glazing on mechanical behaviours and ageing resistance of dental zirconium are gives in [12].

Research in the surface of the dental alloys with cobaltchromium base is presented in [11].TMM foundations are gives in [5]. Other TMM applications for dental bridges are resented in [9] and [10].

\section{DENTAL BRIDGE WITH DENTAL EXTENSION AS A BEAM}

In this work we study a dental bridge with distal extension and with a single pole, as shown in Fig. 1, considered as a beam, as shown in Fig. 2.

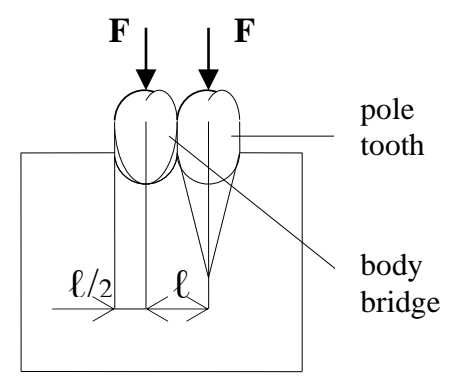

Fig. 1. Dental bridge with distal extension and a single pole

We considered the dental bridge with distal extension and with a single pole as a beam, as shown in Fig. 2.

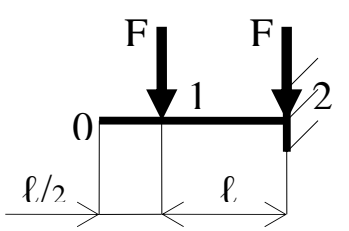

Fig. 2. Dental bridge with distal extension as a beam

Dental bridge is a fixed prosthesis, used in dentistry for morphological restoration given by missing teeth (partial edentulous). 
Also, dental bridge is used for remodelling and protection teeth that have suffered major damages. With help of dental bridges we try to solve three problems, compensating three functions: masticator, phonetic and aesthetic functions, problems due of missing teeth. Also, dental bridges have the role of preventing the possible complications that can appear due to the missing teeth.

Dental bridge consists of two components: aggregation elements with pole teeth and bridge body, which replaces missing teeth. Dental crowns which the bridge rests on the pole tooth represent the aggregation element, as shown in Fig. 1. A dental bridges can by in distal extension (extension to the back of the mouth cavity - posterior part), or in medial extension (extension to the front of the mouth - anterior part).

Dental bridge is required by uniformly distributed theoretical force. The most unfavorable case is given by a concentrated vertical force acting in the middle of bridge body, equivalent to the uniformly distributed load as shown in Fig. 1.

Body of dental bridge and aggregation element and are made together and can thus be considered to be similar to a beam, as shown in Fig. 1 and in Fig. 2.

Aggregation element is stiffened on the pole tooth, allowing assimilation of the stiffener with embedded support. Dental bridge must be constructed so that at maximum loads, the bridge body will not touch the gum.

This work present a study of dental bridge in distal extension assimilated as beam, free at left end and embedded at right end, with two vertical equal loads, which acts as shown in Fig. 1 and Fig. 2, to which we applied the approach gives by Transfer-Matrix Method.

\section{III.BEAM STUDY WITH DIRAC'S AND HEAVISIDE'S FUNCTIONS AND OPERATORS}

We consider a beam, as shown in Fig. 2, free at left end and embedded at right end, with two vertical equal loads.

We applied the approach with Dirac and Heaviside functions and operators. The function of charge density is:

$$
p(x)=-F \delta\left(x-\frac{l}{2}\right)-F \delta\left(x-\frac{3 \cdot l}{2}\right)
$$

We know the equation of the deformed average fiber [6]:

$$
\frac{d^{2} y}{d x^{2}}=-\frac{M(x)}{E I}
$$

which is derived once and gives the cutting force $\mathrm{T}$ :

$$
\frac{d^{3} y}{d x^{3}}=-\frac{1}{E I} \frac{d M(x)}{d x}=-\frac{1}{E I} T(x)
$$

and derived once again from the uniformly distributed load:

$$
\frac{d^{4} y}{d x^{4}}=-\frac{1}{E I} \frac{d^{2} M(x)}{d x^{2}}=-\frac{1}{E I} \frac{d T(x)}{d x}=-\frac{1}{E I} p(x)
$$

(2) integrated once gives the rotation:

$$
\frac{d y}{d x}=-\frac{\omega(x)}{E I}
$$

and integrated once again by the arrow.

(1) is replaced in (4) and we obtain:

$$
\frac{d^{4} y}{d x^{4}}=-\frac{F}{E I} \delta\left(x-\frac{l}{2}\right)-\frac{F}{E I} \delta\left(x-\frac{3 \cdot l}{2}\right)
$$

Relation (6) is integrated successively four times, taking into account the functions and operators of Dirac and Heaviside and we obtain:

$$
\frac{d^{3} y}{d x^{3}}=-\frac{F}{E I} Y\left(x-\frac{l}{2}\right)-\frac{F}{E I} Y\left(x-\frac{3 \cdot l}{2}\right)+A
$$

where:

$$
Y\left(x-\frac{l}{2}\right)
$$

and:

$$
Y\left(x-\frac{3 \cdot l}{2}\right)
$$

are the Heaviside's functions.

After the next three integrations it is obtained successively: $\frac{d^{2} y}{d x^{2}}=-\frac{F}{E I}\left(x-\frac{l}{2}\right) Y\left(x-\frac{l}{2}\right)-\frac{F}{E I}\left(x-\frac{3 \cdot l}{2}\right) Y\left(x-\frac{3 \cdot l}{2}\right)+A x+B$

(10)

$\frac{d y}{d x}=-\frac{F}{2 E I}\left(x-\frac{l}{2}\right)^{2} Y\left(x-\frac{l}{2}\right)-\frac{F}{2 E I}\left(x-\frac{3 \cdot l}{2}\right)^{2} Y\left(x-\frac{3 \cdot l}{2}\right)+$

$+A x^{2}+B x+C$

$y(x)=-\frac{F}{6 E I}\left(x-\frac{l}{2}\right)^{3} Y\left(x-\frac{l}{2}\right)-\frac{F}{6 E I}\left(x-\frac{3 \cdot l}{2}\right)^{3} Y\left(x-\frac{3 \cdot l}{2}\right)+$

$+A x^{3}+B x^{2}+C x+D$

(12)

where A, B, C, D are integration constants and which are determined putting the following conditions at the ends of the beam, as shown in Fig. 2:

$$
\begin{gathered}
\cdot \text { for } x=0 \Rightarrow\left(d^{3} y / d x^{3}\right)(0)=T(0)=0 \\
\cdot \text { for } x=0=>\left(d^{2} y / d x^{2}\right)(0)=M(0)=0 \\
\text { for } x=31 / 2=>(d y / d x)=\omega(31 / 2)=0 \\
\cdot \text { for } x=31 / 2=>y(31 / 2)=0
\end{gathered}
$$

For integration constants calculus must be respect the operating rules of Dirac and Heaviside, [5], and we obtain:

$$
\begin{gathered}
\cdot \text { from }(13) \Rightarrow A=\frac{F}{E I} \\
\cdot \text { from }(14) \Rightarrow B=-\frac{3 F \cdot l}{2 E I} \\
\cdot \text { from }(15) \Rightarrow C=0 \\
\cdot \text { from }(16) \Rightarrow D=0
\end{gathered}
$$

Now, replacing the constants A, B, C, D calculated, with the values given of (17)-(20), in the relations (7), (10), (11 )and (12), we can determine the values of cutting force $\mathrm{T}$, of bending moment $\mathrm{M}$, the rotation $\varphi$ and the arrow $\mathrm{y}$ at all points of beam.

After, this method (used Dirac's and Heaviside's functions and operators) and results, can be used to study and calculus of dental bridge with distal extension and a single pole.

\section{IV.CALCULUS OF DENTAL BRIDGE WITH DISTAL EXTENSION AS A BEAM BY TRANSFER-MATRIX METHOD (TMM)}

A beam, as shown in Fig. 2, can be calculate by an analytical approach, by TMM, based on theory of functions and operators of Dirac and Heaviside, [5], developed in §II.

We consider acting only the bending moment $\mathrm{M}$ and the cutting force $\mathrm{T}$.

For the two concentrated vertical forces $\mathrm{F}$ in points 1 and 2, as shown in Fig. 2, the function of charge density is (1):

$$
p(x)=-F \delta\left(x-\frac{l}{2}\right)-F \delta\left(x-\frac{3 \cdot l}{2}\right)
$$


Free end is noted with 0 (the left end) and embedded support are noted with 2 . With 1 is noted the section where act the vertical concentrated load $\mathrm{F}$, as shown in Fig. 2. The state vector $\{\mathrm{V}\}_{\mathrm{x}}$ with four elements is associated of the section $\mathrm{x}$ :

$$
\{\mathrm{V}\}_{\mathrm{x}}=\{\mathrm{T}(\mathrm{x}), \mathrm{M}(\mathrm{x}), \mathrm{v}(\mathrm{x}), \omega(\mathrm{x})\}^{1}
$$

We have the state vector for the section 0 , at the origin (the left end):

$$
\{\mathrm{V}\}_{0}=\left\{\mathrm{T}_{0}, \mathrm{M}_{0}, \mathrm{v}_{0}, \omega_{0}\right\}^{-1}
$$

We use the following notations: $[\mathrm{TM}]_{\mathrm{x}}-$ the TransferMatrix between the section 0 and the section $\mathrm{x} ;\left\{\mathrm{V}_{\mathrm{e}}\right\}_{\mathrm{x}}-$ the state vector for the free term at the section $x$, which depends on external loads; E - the Young modulus (modulus of longitudinal elasticity); A - area for transversal section of beam; I - moment of inertia. The matrix relation between the state vector of section $\mathrm{x}$ and the state vector for origin section 0 , $\{\mathrm{V}\}_{\mathrm{x}}$ is:

$$
\{\mathrm{V}\}_{\mathrm{x}}=[\mathrm{TM}]_{\mathrm{x}}\{\mathrm{V}\}_{0}+\left\{\mathrm{V}_{\mathrm{e}}\right\}_{x}
$$

General approach is presented in [5]. The developed relationship is

$$
\left\{\begin{array}{l}
T(x) \\
M(x) \\
v(x) \\
\omega(x)
\end{array}\right\}=\left[\begin{array}{cccc}
1 & 0 & 0 & 0 \\
-x & 1 & 0 & 0 \\
-\frac{x^{3}}{6 E I} & \frac{x^{2}}{2 E I} & 1 & x \\
-\frac{x^{2}}{2 E I} & \frac{x}{E I} & 0 & 1
\end{array}\right]\left\{\begin{array}{l}
T_{0} \\
M_{0} \\
v_{0} \\
\omega_{0}
\end{array}\right\}+\left\{\begin{array}{l}
-F \\
-F\left(x-\frac{l}{2}\right) \\
-\frac{F}{6 E I}\left(x-\frac{l}{2}\right)^{3} \\
-\frac{F}{2 E I}\left(x-\frac{l}{2}\right)^{2}
\end{array}\right\}
$$

At the right end of the beam, the relation (25), referring to $x=31 / 2$, we can write (26):

$$
\left\{\begin{array}{c}
T\left(\frac{3 \cdot l}{2}\right) \\
M\left(\frac{3 \cdot l}{2}\right) \\
v\left(\frac{3 \cdot l}{2}\right) \\
\omega\left(\frac{3 \cdot l}{2}\right)
\end{array}\right\}=\left[\begin{array}{c}
\frac{1}{-\frac{3 \cdot l}{2}} \\
-\frac{\left(\frac{3 \cdot l}{2}\right)^{3}}{6 E I} \\
\left.-\frac{3 \cdot l}{2}\right)^{2} \\
-\frac{(2 E I}{2}
\end{array}\right.
$$$$
\frac{\left(\frac{3 \cdot l}{2}\right)^{2}}{\frac{1}{2 E I}}
$$$$
\left.\begin{array}{ll}
0 & 0 \\
0 & 0 \\
1 & \frac{3 \cdot l}{2} \\
0 & 1
\end{array}\right\}\left\{\begin{array}{l}
T_{0} \\
M_{0} \\
v_{0} \\
\omega_{0}
\end{array}\right\}+\left\{\begin{array}{l}
-F \\
-F\left(\frac{3 \cdot l}{2}-\frac{l}{2}\right) \\
-\frac{F}{6 E I}\left(\frac{3 \cdot l}{2}-\frac{l}{2}\right)^{3} \\
-\frac{F}{2 E I}\left(\frac{3 \cdot l}{2}-\frac{l}{2}\right)^{2}
\end{array}\right\}
$$

After calculus, we obtain:
In relation (27), we replace (28) and (29) and we obtain:

$$
\left\{\begin{array}{l}
T\left(\frac{3 \cdot l}{2}\right) \\
M\left(\frac{3 \cdot l}{2}\right) \\
0 \\
0
\end{array}\right\}=\left[\begin{array}{cccc}
1 & 0 & 0 & 0 \\
-\frac{3 \cdot l}{2} & 1 & 0 & 0 \\
-\frac{9 \cdot l^{3}}{16 E I} & \frac{9 \cdot l^{2}}{8 E I} & 1 & \frac{3 \cdot l}{2} \\
-\frac{9 \cdot l^{2}}{8 E I} & \frac{3 \cdot l}{2 E I} & 0 & 1
\end{array}\right]\left\{\begin{array}{l}
0 \\
0 \\
v_{0} \\
\omega_{0}
\end{array}\right\}+\left\{\begin{array}{l}
-F \\
-F \cdot l \\
-\frac{F \cdot l^{3}}{6 E I} \\
-\frac{F \cdot l^{2}}{2 E I}
\end{array}\right\}
$$

We have a linear system of four equations with four unknowns of form:

$$
\left\{\begin{array}{l}
T\left(\frac{3 l}{2}\right)=-F \\
T\left(\frac{3 l}{2}\right)=-F \cdot l \\
0=v_{0}+\frac{3 \cdot l}{2} \omega_{0}-\frac{F \cdot l^{3}}{6 E I} \\
0=\omega_{0}-\frac{F \cdot l^{2}}{2 E I}
\end{array}\right.
$$

and solutions (32):

$$
\left\{\begin{array}{l}
T\left(\frac{3 l}{2}\right)=-F \\
M\left(\frac{3 l}{2}\right)=-F \cdot l \\
v_{0}=-\frac{7 F l^{3}}{12 E I} \\
\omega_{0}=\frac{F \cdot l^{2}}{2 E I}
\end{array}\right.
$$

identical to those obtained from classical calculus [6]. So, the maximum cutting force is at aggregation element and body of dental bridge, and the maximum moment is taken by the pole tooth.

\section{CONCLUSIONS}

In first part of this work, we present calculus of a beam as shown in Fig. 2, with an approach consisting in a method based on Dirac's and Heaviside's functions and operators. In second parts, we present a calculus of the same beam by TMM. The TMM algorithm can be very easy programmed and we can obtain all components for all state vectors for all sections: stresses and strains. This work propose a special approach, an original approach, for orthodontic problems, in occurrence for a dental bridge in distal extension and with a single pole tooth by assimilating the dental bridges with a beams studied by TMM. This algorithm can be extended for other cases for dental bridges. In future research, we hope to present experimental validation of results too.

\section{REFERENCES}

[1] A.-I. Botean, Study of changing geometric characteristics in proximal femoral bone affected by osteoporosis in compliance with Singh index, Acta Technica Napocensis, Series: Applied Mathematics and Mechanics, Vol. 60, Issue III, September 2016, 2016.

[2] F. J. T. Burke, P. S. K. Lucarotti, Ten year survival of bridges placed in the General Dental Services in England and Wales, Journal of Dentistry, 
vol. 40, Issue 11, https://doi.org/10.1016/j.jdent.2012.07.002, 2012.

[3] T. Dikova and T. Vasilev, Bending fracture of $\mathrm{Co}-\mathrm{Cr}$ dental bridges, produced by additive technologies: Simulation analysis and test, Engineering Fracture Mechanics 218/2019, https://doi.org/10.1016/j.engfracmech.2019.106583, 2019.

[4] T. Dikova, Bending fracture of $\mathrm{Co}-\mathrm{Cr}$ dental bridges, produced by additive technologies: experimental investigation, Procedia Structural Integrity 13/2018, 461-468, Elsevier B.V. Peer-review under responsibility of the ECF22 organizers, 10.1016/j.prostr.2018.12.077, 2018.

[5] P. M. Gery and J.-A. Calgaro, Les Matrices-Transfert dans le calcul des structures, Editions Eyrolles, Paris, 1987.

[6] M. Suciu and M, Tripa, Strength of Materials, Ed. UTPress, ClujNapoca, 2016.

[7] R. Studart, F. Filser, P. Kocher, L. J. Gauckler, Fatigue of zirconia under cyclic loading in water and its implications for the design of dental bridges, Dental Materials 23/2007, 106-114, doi: 10.1016/j.dental.2005.12.008, 2007.

[8] M. Tripa et allii, About buckling calculus of straight bars on elastic environment by Transfer-Matrix Method (TMM) for dental implants, MATEC Web of Conferences 178, 04007 (2018), https://doi.org/10.1051/matecconf/201817804007, 2018. IManE\&E, 2018.

[9] M. Tripa et allii, About the study of frames by Transfer-Matrix Method (TMM)-similarity of dental bridges with frames, ATN, Cluj-Napoca, 2019.

[10] M. Tripa et allii, Analytical study of dental bridge by similarity to a beam by Transfer-Matrix Method (TMM), ATN, Cluj-Napoca, 2019.

[11] W. A. Uriciuc, H. Vermesan, A. I. Botean, L. Nistor, C. Popa, Research in the surface of the dental alloys with cobalt-crom base, ATN, ClujNapoca, 2019.

[12] Xuan Lai, Wenjie Si, Danyu Jiang, Ting Sun, Longquan Shao, Bin Deng: Effects of small-grit grinding and glazing on mechanical behaviors and ageing resistance of a super translcent dental zirconia, Journal of Dentistry, 66/2017, pp. 23-31, http://dx.doi.org/10.1016/j.jdent.2017.09.003, 2017. 